\title{
Os desafios do trabalho na contemporaneidade
}

Esta seção temática foi organizada com contribuições de pesquisadores que participaram do IV Colóquio Internacional da Clínica da Atividade (IV CICA), realizado entre os dias 12 e 14 de novembro de 2019, na Universidade São Francisco, Campus Bragança Paulista. O evento teve como objetivo geral refletir sobre os desafios do trabalho na contemporaneidade, buscando, no diálogo entre os pesquisadores, compreender as contribuições da Clínica da Atividade na análise da atividade e os possíveis impactos dessa análise na (re)organização do trabalho. Tais objetivos foram alcançados, considerando a forma como a programação foi idealizada, os temas discutidos bem como com a ampla participação de pesquisadores e estudantes.

Essa edição do evento contou com a presença de três pesquisadores estrangeiros: Yves Clot e Katia Kostulski, do Conservatoire National des Arts et Métiers (CNAM - Paris/FR) e o professor Frédéric Saussez da Universidade de Sherbrook (Canadá). Contou também com a presença de pesquisadores de várias universidades brasileiras tais como: Jorge Falcão e Flávio Fontes, da Universidade Federal do Rio Grande do Norte; Rozania Moraes, da Universidade Estadual do Ceará; Anselmo Lima, da Universidade Tecnológica Federal do Paraná; Daisy Cunha, da Universidade Federal de Minas Gerais; Maria Elizabeth Antunes Lima, do Centro Universitário Novos Horizontes; Cláudia Osório, da Universidade Federal Fluminense, e pesquisadores do Estado de São Paulo tais como: Ana Luiza Smolka, Selma Venco e Luci Banks-Leite da Universidade Estadual de Campinas; Eliane Lousada, Marcia Hespagnol, Laerte Idal Sznelwar da Universidade de São Paulo, além das professoras e pesquisadoras da USF, Grazielle Bertolini, Daniela Dias dos Anjos, Ermelinda Barricelli, Luzia Bueno e Katia Diolina. ${ }^{1}$

Os artigos que compõem este número representam uma síntese das ricas discussões que ocorreram durante o colóquio.

O texto de abertura é um ensaio, escrito por Yves Clot, intitulado "Le travail «ni fait ni à faire»: un risque pour la santé publique en France", no qual o autor faz uma rica reflexão sobre as relações entre a deterioração da saúde ocupacional e a deterioração da saúde pública, no

\footnotetext{
${ }^{1}$ A programação completa do evento pode ser encontrada em: https://sites.google.com/usf.edu.br/cica4/programação
} 
contexto atual.

O artigo "A perspectiva histórico-cultural como orientação para a análise do trabalho desafios do trabalho pedagógico na contemporaneidade", de Ana Luiza Smolka, tem como objetivo a reflexão sobre o trabalho docente pela perspectiva histórico-cultural do desenvolvimento humano e o exame de pressupostos teóricos e epistemológicos de base marxiana que tem sustentado estudos e pesquisas sobre o assunto, no Brasil.

Em "Elementos de psicologia geral e do trabalho em relação biunívoca", Jorge Falcão objetiva contribuir para a proposição de uma psicologia geral capaz de fazer face à crise que presidiu seu surgimento, bem como refletir sobre a plausibilidade de uma psicologia do trabalho fundamentada na psicologia histórico-cultural.

Daisy Moreira Cunha, em seu artigo "O enigma da atividade humana convoca clínicas do trabalho" apresenta interrogações, problemas e compartilhamentos epistemológicos comuns entre a Abordagem Ergológica do Trabalho e a da Clínica da Atividade por meio de uma revisão conceitual e teórico-metodológica das contribuições de seus principais autores.

O texto de Flávio Fontes, intitulado: "A abordagem clínica e o conceito de atividade", apresenta uma descrição ampla da abordagem clínica em ciências humanas a partir da psicanálise e das clínicas do trabalho e explicita suas diferenças em relação à pesquisa positivista. Investiga ainda como o conceito de atividade se relaciona com a perspectiva clínica ao enfatizar o desconhecimento inerente ao fazer humano.

Em seguida, o artigo "Clínica da atividade e análise institucional: intercessões possíveis" de Claudia Osorio da Silva, Fernanda Spanier Amador e Tatiane Oliveira, explora possíveis intercessões da clínica da atividade com princípios e conceitos da análise institucional. Segundo as autoras, há entre essas abordagens, uma base epistemológica comum, na qual se destacam a importância do princípio de transformar para conhecer e o foco da análise nas tensões que habitam o campo analisado.

Giselle Reis Brandão, Maria Elizabeth Antunes Lima, Renata Bastos Ferreira Antipoff, no texto "A observação como método de análise do trabalho - diferentes modos de apropriação", apresentam um ensaio que trata dos diferentes modos de apropriação da técnica de observação no contexto da Saúde Mental e Trabalho, da Ergonomia e da Clínica da Atividade. As autoras propõem um diálogo entre esses campos do conhecimento a partir das suas bases teóricas, seus 
objetos de estudo e seus propósitos fundamentais, tendo por foco o modo pelo qual recorrem à observação.

O artigo de Mylène Zittoun e Yves Clot, "Uma intervenção em uma instituição de longa permanência para idosos: a animação recíproca da discussão", apresenta como o trabalho inicial de coanálise da atividade dos profissionais em autoconfrontação cruzada permitiu instituir, por um lado, a função do coletivo de trabalho como meio de ação na organização e, por outro lado, as instâncias de deliberação e decisão sobre o métier.

Durante o colóquio, vários foram os trabalhos voltados para análise da atividade docente. Buscando contribuir para uma melhor compreensão das condições de trabalho dos professores, Selma Venco apresenta o texto "Professores da educação básica rumo à uberização ou ao desemprego? Uma análise das relações de trabalho nas escolas estaduais da região metropolitana de Campinas". A autora apresenta uma pesquisa de caráter documental que analisou um fenômeno característico da Nova Gestão Pública, à luz da localização das escolas no território e busca interrogá-lo, no sentido de compreender os caminhos futuros da profissão.

A perspectiva da Clínica da Atividade tem oferecido contribuições relevantes para estudos sobre o trabalho no campo da educação e formação de professores. Nesse sentido, Siderlene Muniz-Oliveira, Anselmo Pereira de Lima e Dalvane Althaus, apresentam uma proposta de implementação de uma Clínica da Atividade Docente, a partir de uma experiência vivenciada em uma universidade pública.

A partir de pesquisa realizada com professoras alfabetizadoras, Ana Lucia Horta Nogueira problematiza a articulação das instâncias de pesquisa, intervenção e formação profissional, como lócus de desenvolvimento profissional, no texto "Como analisar o métier do professor alfabetizador? Contribuições teórico-metodológicas da perspectiva histórico-cultural e da clínica da atividade".

O artigo "O papel da língua materna no ensino do francês como língua estrangeira: uma velha questão rediscutida à luz das ciências do trabalho" de Eliane Lousada, objetiva apresentar um estudo sobre verbalizações de professores de francês, produzidas pelo método da autoconfrontação, procurando refletir sobre o papel da LM no trabalho de ensinar uma LE.

Rozania Maria Alves de Moraes, Marina Cavalcanti Tavares Clemente e Luciana Peixoto Bessa, no texto "O papel dos afetos na atividade docente: a experiência de um professor diretor 
de turma de ensino médio", apresentam análises de uma pesquisa em curso acerca do papel dos afetos na atividade de um professor de português numa escola de ensino médio, onde também atua como diretor de turma. O objetivo foi o de analisar como os afetos se manifestam pela atividade linguageira desse professor em uma situação de autoconfrontação.

O texto "Os conflitos nos desdobramentos de uma Intervenção em Clínica da Atividade em contexto escolar", de Ermelinda Barricelli, Katia Diolina e Daniela Anjos discute os conflitos desencadeados nos desdobramentos de uma intervenção que ocorreu de 2014 a 2020 no contexto da Educação Infantil. A partir das análises, constatou-se o quanto o trabalho dos professores e dos gestores sofre com conflitos de dimensões distintas: pessoais, impessoais, interpessoais e, particularmente, transpessoais.

Finalmente, trazemos também o podcast "Saúde Mental e Trabalho", com uma aula proferida por Maria Elizabeth Antunes Lima na qual, entre outras questões, ela tece considerações sobre a saúde no contexto da pandemia da Covid-19. Clique aqui para acessar².

Quando o tema "desafios do trabalho na contemporaneidade" foi escolhido para o IV CICA, jamais seus idealizadores poderiam imaginar a enorme transformação que os contextos laborais e o cotidiano das pessoas iriam sofrer, em nível planetário e em um curto espaço de tempo. Apenas alguns meses após sua realização, fomos todos surpreendidos com a pandemia da Covid19, uma experiência sem precedentes para a humanidade, tamanha a rapidez e a violência com as quais o vírus alcançou todo o planeta. Com a adoção do isolamento físico de grande parte das pessoas, como medida preventiva, mudanças radicais foram impostas ao mundo do trabalho e novos desafios se impuseram aos assalariados, mas também aos profissionais autônomos. As empresas e organizações em geral que tiveram condições para isso, passaram a adotar, com boa parte dos empregados, o sistema de trabalho remoto ou home office, como nos habituamos a chamar aqui no Brasil. Isso acarretou uma reformulação importante na forma de cada um organizar e realizar suas atividades, sendo que tal experiência nem sempre é percebida como positiva. Se, por um lado, essa nova modalidade de trabalho libera o indivíduo do incômodo do deslocamento até a empresa e o protege de um possível contágio pelo vírus, por outro, o expõe

${ }^{2}$ https://soundcloud.com/corujalusf/ep-02-saude-mental-e-trabalho 
a uma jornada mais extensa, além de ocorrer uma intensificação do esforço cotidiano, devido à sobreposição das atividades profissionais e domésticas.

Aqueles que não tiveram a possibilidade de realizar seu trabalho no espaço doméstico também foram obrigados a mudar drasticamente sua rotina diária, devendo adotar medidas rigorosas de proteção, já que estão mais expostos ao vírus. A maioria faz parte dos grupos que compõem as atividades ditas essenciais e, portanto, tiveram de continuar a trabalhar, mesmo cientes dos riscos aos quais estão expostos. São também aqueles que têm aparecido nas estatísticas como os mais atingidos pela pandemia.

O uso intensivo da tecnologia digital, o distanciamento social, o medo do desconhecido, têm gerado novas formas de desgaste e de comprometimento da saúde física e mental nesses diversos contextos laborais, cuja compreensão necessita, sem dúvida, ser mais aprofundada. Isto significa que, alguns problemas tratados no âmbito do colóquio e nos artigos que compõem este número da revista, provavelmente, já se apresentam de outra forma, mostrando-se talvez mais acentuados ou com nuances impossíveis de serem detectadas nas circunstâncias anteriores. Mas esta não é uma questão para ser tratada aqui, sendo talvez um bom tema para o próximo encontro.

Neste momento, nossa pretensão, ao trazer a público este número especial da revista Horizontes, é tão somente a de retratar da forma mais fiel possível o contexto do IV CICA, esperando que nosso intento tenha sido bem-sucedido. Convidamos aos interessados pelo tema a fazerem sua própria avaliação e desejamos a todos uma boa leitura!

Daniela Dias dos Anjos Maria Elizabeth Antunes Lima 